\title{
Micronutrients in childhood and the influence of subclinical inflammation
}

\author{
David I. Thurnham ${ }^{1 *}$, Anne S.W. Mburu ${ }^{2}$, David L. Mwaniki ${ }^{2}$ and Arjan De Wagt $^{3}$ \\ ${ }^{1}$ Northern Ireland Centre for Food and Health, School of Biomedical Sciences, University of Ulster, Coleraine BT52 1SA, \\ County Londonderry, UK \\ ${ }^{2}$ Kenya Medical Research Institute, Centre for Public Health Research, Nairobi, Kenya \\ ${ }^{3}$ UNICEF East Asia and Pacific Regional Office, Bangkok, Thailand
}

\begin{abstract}
In the present paper biomarkers of micronutrient status in childhood and some of the factors influencing them, mainly dietary intake, requirements and inflammation will be examined. On a body-weight basis the micronutrient requirements of children are mostly higher than those of an adult, but most biomarkers of status are not age-related. A major factor that is often overlooked in assessing status is the influence of subclinical inflammation on micronutrient biomarkers. In younger children particularly the immune system is still developing and there is a higher frequency of sickness than in adults. The inflammatory response rapidly influences the concentration in the blood of several important micronutrients such as vitamin $\mathrm{A}, \mathrm{Fe}$ and $\mathrm{Zn}$, even in the first $24 \mathrm{~h}$, whereas dietary deficiencies can be envisaged as having a more gradual effect on biomarkers of nutritional status. The rapid response to infection may be for protective reasons, i.e. conservation of reserves, or by placing demands on those reserves to mount an effective immune response. However, because there is a high prevalence of disease in many developing countries, an apparently-healthy child may well be at the incubation stage or convalescing when blood is taken for nutritional assessment and the concentration of certain micronutrient biomarkers will not give a true indication of status. Most biomarkers influenced by inflammation are known, but often they are used because they are convenient or cheap and the influence of subclinical inflammation is either ignored or overlooked. The objective of the present paper is to discuss: (1) some of the important micronutrient deficiencies in childhood influenced by inflammation; (2) ways of correcting the interference from inflammation.
\end{abstract}

Micronutrients: Children: Infants: Inflammation

Childhood malnutrition is an enormous problem in the developing world and the dietary supply of vitamin A, $\mathrm{Fe}, \mathrm{Zn}$ and $\mathrm{I}$ is marginal to deficient in many countries. To address the situation micronutrient supplementation and food fortification programmes are being widely used to combat the problems of micronutrient malnutrition both in the developing and developed world. Assessing the scale of the problem or the success of an intervention requires nutritional biomarkers, and in the present paper factors affecting the interpretation of these biomarkers will be discussed. Children present particular problems. In comparison with adults, children have higher nutrient requirements and are highly susceptibility to disease. Tests of micronutrient status have generally been established from studies using healthy adults. While the tests are relevant, they must be interpreted with caution. Children are not adults and are often not healthy. Subclinical inflammation in apparently-healthy children can lead to misinterpretation of nutritional status and an overestimate of those with deficiencies (Brown et al. 1993; Thurnham et al. 2003). It is probably not a coincidence that the micronutrient deficiencies that are reported to be most common in developing countries, i.e. vitamin A, $\mathrm{Fe}, \mathrm{I}$ and $\mathrm{Zn}$, are strongly influenced by infection (Thurnham, 1997; Thurnham \& Northrop-Clewes, 2004). The question that will be discussed in the present paper is how to correct for disease exposure in assessing micronutrient status.

Abbreviations: ACT, $\alpha 1$-antichymotrypsin; AGP, $\alpha 1$-acid glycoprotein; CRP, C-reactive protein

*Corresponding author: Professor D. I. Thurnham, present address 47 Knocknougher Road, Macosquin, Coleraine BT51 4LA, UK, fax + 442870 324965, email di.thurnham@ulster.ac.uk 
Table 1. Comparison of dietary requirements of some micronutrients in children and adult men (units $/ \mathrm{kg}$ )

\begin{tabular}{lcc}
\hline Nutrient & Child 2 years $^{*}$ & $\begin{array}{c}\text { Adult man } \\
19-50 \text { years }^{*}\end{array}$ \\
\hline Vitamin A $(\mu \mathrm{g} / \mathrm{d})$ & 35 & 10 \\
Fe $(\mathrm{mg} / \mathrm{d})$ & 0.8 & 0.12 \\
$\mathrm{Zn}(\mathrm{mg} / \mathrm{d})$ & 0.5 & 0.14 \\
$\mathrm{I}(\mu \mathrm{g} / \mathrm{d})$ & 7.0 & 2.0 \\
Thiamin $(\mu \mathrm{g} / \mathrm{d})$ & 0.05 & 0.01 \\
Riboflavin $(\mu \mathrm{g} / \mathrm{d})$ & 0.06 & 0.02 \\
Niacin $(\mathrm{NE} / \mathrm{d})$ & 0.8 & 0.23 \\
Vitamin C $(\mu \mathrm{g} / \mathrm{d})$ & 3.0 & 0.57 \\
Folate $(\mu \mathrm{g} / \mathrm{d})$ & 7.0 & 2.9 \\
\hline
\end{tabular}

$\mathrm{NE}$, niacin equivalents.

*Data calculated assuming $10 \mathrm{~kg}$ for the child and $70 \mathrm{~kg}$ for an adult man (Department of Health, 1991).

\section{Principal factors influencing micronutrient status in children}

\section{Nutrient requirements and disease}

On a body-weight basis, the nutrient requirements of children are higher than those of an adult. The values shown in Table 1 are calculations of nutrient requirements on a per $\mathrm{kg}$ basis for a child of 2 years, assuming a weight of $10 \mathrm{~kg}$, and an adult man weighing $70 \mathrm{~kg}$ using data from the report of the UK Department of Health (1991). These data suggest that children need three to six times more nutrients per $\mathrm{kg}$ body weight than an adult. Higher requirements mean the risk of micronutrient deficiencies will increase where nutrient-dense foods, i.e. often those of animal origin, are expensive or unobtainable. Infants are often weaned onto starchy paps that contain low concentrations of nutrients, high concentrations of phytate that compete with the absorption of minerals and often very little vitamin $\mathrm{A}$ in the form of vegetables. If those problems are not enough, children are also very susceptible to disease that can both increase requirements as well as causing anorexia to reduce food intake.

Poverty, unsanitary conditions and inadequate health care encourage the spread of disease and increase exposure of infants and children to disease. Thus, it is not surprising that diarrhoea, respiratory diseases, skin diseases and malaria are common in developing countries. Children are born with very little protection against pathogens but need exposure to pathogens in order to develop their own immune defences. Infants acquire some protection from Ig and other factors in their mother's milk, and in time they acquire their own immune defences. They are, however, sick for a very large part of their early lives (Sepulveda et al. 1988; Filteau et al. 1995). Rowland et al. (1977) have reported that Gambian infants may spend $13 \%$ of the year with gastrointestinal disease and $10 \%$ of the year with upper respiratory tract infections. Shankar et al. (1999) have reported that $>40 \%$ of all children aged 1-5 years in the Wosera area of Papua New Guinea are infected by Plasmodium falciparum-related malaria. On average children are bitten by malaria-positive mosquitos four times weekly. In such circumstances children are frequently sick until they acquire some immunity, but even when they no longer succumb to the parasite they will still need to mount an immune response each time foreign material enters their blood stream and will consequently display the effects of subclinical inflammation in their blood and other tissues.

Low intakes of animal foods or carotene-containing foods and diets containing a high content of phytate are very likely to result in deficiencies of vitamin $\mathrm{A}, \mathrm{Fe}$ and Zn. Such deficiencies may not immediately lower concentrations of biomarkers in the circulation or cause clinical evidence of disease, but tissue stores or reserves may be depleted and/or growth may be restricted by a limiting essential nutrient (Golden, 1991). In contrast, disease or stress can very rapidly lower the concentration of circulating biomarkers. Plasma retinol concentrations decrease by approximately $25 \%$ within $4 \mathrm{~h}$ in adults undergoing minor surgery and continue to fall over the next $3 \mathrm{~d}$ (Louw et al. 1992), while plasma $\mathrm{Fe}$ and $\mathrm{Zn}$ concentrations have been reported to fall by $50-70 \%$ in the first $24 \mathrm{~h}$ following experimental infections of army recruits with sandfly fever (Beisel, 1976). In addition, plasma retinol has frequently been reported to be low (Reddy et al. 1986; Thurnham \& Singkamani, 1991) and sometimes very low (Mitra et al. 1998; Cser et al. 2004) in children with various infections, and spontaneously increases on recovery without vitamin A intervention. As infection can cause such rapid changes in the concentration of biomarkers such as plasma retinol, $\mathrm{Fe}$ and $\mathrm{Zn}$, it is important to determine that residual alterations caused by infection are not still present in infants recruited on surveys that assess nutritional status.

In the case of plasma retinol there is also a very marked increase in concentrations with increasing age. Data from preschool children (Gregory et al. 1995), children and adolescents (Gregory et al. 2000) and adults (Gregory et al. 1990) living in the UK are combined in Fig. 1. A very similar picture can be constructed from US data (Ballew et al. 2001). Gender-related differences in plasma retinol concentrations do not appear until children reach

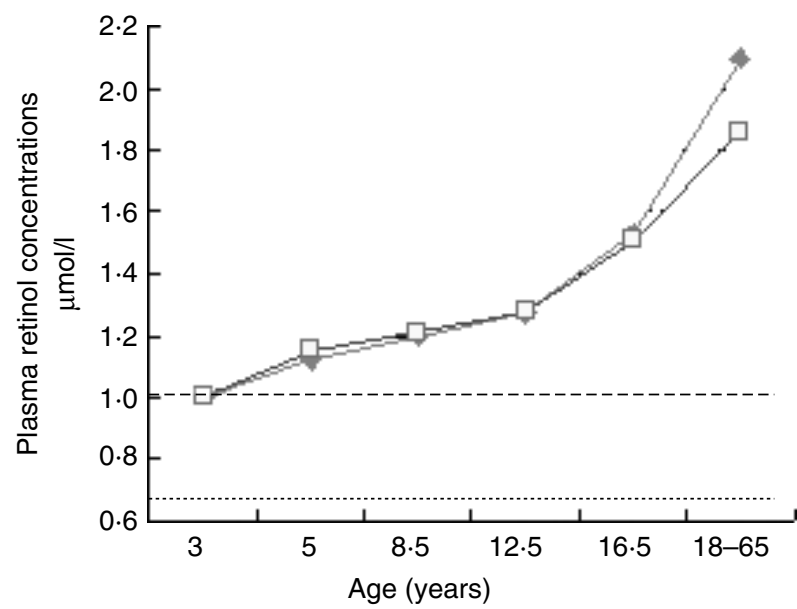

Fig. 1. Mean retinol concentrations at different ages for males and females obtained from three UK national surveys (Gregory et al.

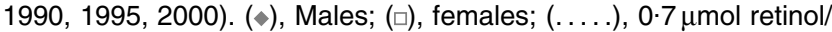
I; $(---), 1.05 \mu \mathrm{mol}$ retinol/I (the two retinol concentrations represent the cut-off values used to indicate risk of vitamin A deficiency; for discussion, see text). 
late adolescence and into adulthood, when concentrations in men are usually higher than those in women. Assessment of status is usually based on the proportion of subjects with a plasma retinol concentration $<0 \cdot 7 \mu \mathrm{mol} / \mathrm{l}$. If the low retinol concentration is the result of a dietary deficiency, then at this concentration in the plasma the liver stores of retinol could be borderline at approximately $20 \mu \mathrm{g} / \mathrm{g}$ (De Luca et al. 1977). If, on the other hand, plasma retinol concentrations are low as a result of concurrent inflammation, then liver stores of vitamin A may not be at a critical state but mobilisation of vitamin $\mathrm{A}$ is suppressed as a result of a down-regulation of retinolbinding protein synthesis that is also a consequence of inflammation (Rosales et al. 1996). In terms of nutritional status both situations probably represent a deficient state for children but each situation may require a different solution to improve nutritional status. In children in areas in which malaria is heavily endemic (Shankar et al. 1999) and in HIV-1-positive women showing evidence of inflammation (Baeten et al. 2002) plasma retinol concentrations do not respond particularly well to vitamin A supplements. In contrast, in the HIV-1-positive women with no evidence of inflammation the plasma retinol concentrations show an increase in response to vitamin A supplements (Baeten et al. 2002).

In adults a plasma concentration of $<1.05 \mu \mathrm{mol} \mathrm{retinol} / \mathrm{l}$ is sometimes used to indicate risk of vitamin A deficiency (Pilch, 1985), but at this concentration evidence suggests that liver stores of vitamin A are probably adequate. Thus, the plasma retinol concentration of $0.7 \mu \mathrm{mol} / 1$ is probably equally suitable as a criterion of risk for all groups in the community.

\section{Measuring subclinical inflammation in the apparently-healthy child}

Children who are sick would automatically be excluded from surveys in which nutritional status is being examined. Surveys recruit only apparently-healthy children and, with a few exceptions, it is generally assumed that recent disease has very little or no effect on the results. However, there is ample evidence to show that even apparentlyhealthy children can have elevated inflammatory markers. Rousham et al. (1998) have found that apparently-healthy Bangladeshi preschool children whose mothers' reported diarrhoea or fever in their child in the previous 2 weeks have elevated $\alpha 1$-antichymotrypsin (ACT) concentrations. Fever and persistent diarrhoeas are common early symptoms in HIV-infected children (Dobosz \& Marczynska, 2004), and Filteau et al. (1995) have also found diarrhoea in the previous week to be associated with several elevated acute-phase proteins in preschool Ghanaian children. Panter-Brick et al. (2001) have reported that stunting is associated with high plasma ACT concentrations in Nepali village children even though morbidity appears to be low. Northrop-Clewes et al (1994) have also reported that mean plasma ACT concentrations are elevated in $>50 \%$ of apparently-healthy Gambian infants every month over 1 year. In the rainy season it was found that the mean concentration of ACT is so high that it indicates that most infants show evidence of subclinical inflammation
(Thurnham et al. 2000). Similarly, in an area like Papua New Guinea, or anywhere where there is high malaria transmission (Shankar et al. 1999), it is highly likely that subclinical inflammation is present in many individuals in the community and probably accounts for the very poor response in plasma retinol concentrations in children to four vitamin A doses of $60 \mathrm{mg}$ retinol equivalent in a period of 1 year.

There are three acute-phase proteins that have been used to measure subclinical inflammation in several nutrition studies: ACT; C-reactive protein (CRP); $\alpha 1$-acid glycoprotein (AGP; Thurnham et al. 2003). ACT is a good general marker of both acute and chronic disease. It rises rapidly and remains elevated for some time after clinical symptoms disappear. Plasma CRP increases rapidly within $5 \mathrm{~h}$ of infection. It is maximal between 24 and $48 \mathrm{~h}$ and falls rapidly with disappearance of symptoms. Plasma AGP concentration is slower to rise and it is unusual to detect an elevation before $48 \mathrm{~h}$. It does not reach maximal concentrations until 4-5d following infection, but there appears to be no information on how long it will remain elevated following different infections. However, any increase in AGP may also indicate that plasma retinol concentrations are still being depressed by the acute-phase response.

\section{Correcting plasma retinol concentrations using plasma concentrations of inflammatory biomarkers}

The first attempt to correct nutritional data for the influence of subclinical inflammation in order to assess the separate impacts of dietary deficiency and inflammation on plasma retinol concentrations was done using the two proteins ACT and AGP (Paracha et al. 2000). Plasma ACT concentrations were found to be elevated in $11 \%$ (274 of 2519) of Pakistani preschool children while elevated AGP concentrations were present in almost half the children $(45 \% ; 1141$ of 2519$)$. It is possible by using two acute-phase proteins that respond differently over the time-course of the infection to characterise three stages of subclinical inflammation, i.e. incubation and early and late convalescence. In subsequent work the use of CRP rather than ACT has been favoured, as CRP has a shorter time span of elevation than ACT; i.e. CRP identifies early convalescence better than ACT because CRP overlaps with elevated AGP concentrations for a shorter period than ACT. Fig. 2 illustrates diagrammatically how the three phases of subclinical inflammation are identified using the acute-phase proteins. Subjects in whom there are no elevated acute-phase proteins provide the reference or 'healthy' group for whom it is assumed that diet is the main factor responsible for the concentration of the biomarker. The influence of inflammation on a nutritional biomarker is determined by calculating the differences between median biomarker concentrations of the 'healthy' group and each of the groups with raised acute-phase proteins. A meta-analysis of fifteen studies, mostly of infants or children, has used these methods to calculate the depression in plasma retinol where inflammation is present and provide the factors required to normalise plasma retinol concentrations to remove the effects of inflammation 


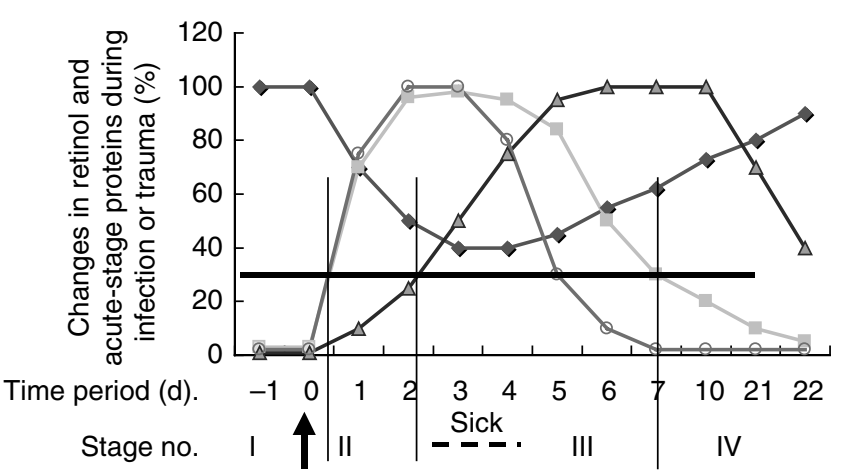

Fig. 2. Idealised behaviour of acute-phase proteins during the course of infection. Standardised changes in plasma retinol $(\bullet)$, C-reactive protein (CRP; o), $\alpha 1$-antichymotrypsin (ACT; $\square$ ) and $\alpha 1$-acid glycoprotein (AGP; $\Delta$ ) in response to trauma or infection $(t)$. (-), Threshold. The values depicting the changes should not be taken as absolute. The four stages of infection are: I, healthy or reference; II, incubation; III, early convalescence; IV, late convalescence; as indicated by abnormal elevations in CRP (or ACT) and/or AGP (see Table 2). The time period (d) shown is arbitrary and variable, except for stage II, which is unlikely to be $>48 \mathrm{~h}$.

(Table 2; Thurnham et al. 2003). Furthermore, it was pointed out that the corrections normalise the mean or median plasma retinol concentrations in all three groups in which inflammation is present, to that of the reference or healthy group. Thus, the need to do the correction will depend on the size of the reference group relative to the total population. In the industrial world there are likely to be very few subjects with elevated acute-phase proteins $(<15 \%)$, this group will therefore be small and can simply be removed from the analysis. It should be noted, however, that an appropriate threshold should be used to evaluate the effects of CRP concentrations on plasma biomarkers. Clinicians use a cut-off of $10 \mathrm{mg} / \mathrm{l}$, as this value relates better to the clinical relevance of the data. However, healthy subjects tend to display plasma CRP concentrations $<5 \mathrm{mg} / \mathrm{l}$, thus CRP values between 5 and $10 \mathrm{mg} / \mathrm{l}$ probably indicate mild inflammation and such subjects could be assigned to either groups II (incubating or preclinical) or III (early convalescence; Fig. 2), which show a correspondingly low plasma retinol concentration. Furthermore, if plasma AGP concentrations are not measured, a potentially large group of subjects in late-stage convalescence may be missed (Paracha et al. 2000). Thus, in any nutritional survey, especially in developing countries, information on both acute and chronic acute-phase markers is desirable to enable a proper interpretation of the nutritional data.

Interpretation of plasma retinol concentrations in apparently-healthy HIV-1-positive adults and comparisons with HIV-negative infants

The first opportunity to test the correction factors obtained in the meta-analysis on the vitamin A studies was on baseline data from a group of apparently-healthy HIV-1positive adults (Thurnham DI, Mburu ASW, Mwaniki DL, Muniu EM, Alumasa F \& de Wagt A, unpublished results). The subjects were recruited for an intervention study to determine whether a food supplement with or without supplemental multiple micronutrients would improve the general health and well-being and quality of life of adult men and women living with HIV (Mburu et al. 2004). The median concentrations of plasma retinol for the group are shown in Table 3, grouped according to their acute-phase status. Following correction using the factors from the meta-analysis, median retinol concentration for the whole group was $1.31 \mu \mathrm{mol} / 1$ and the proportion of results that were $<0.7 \mu \mathrm{mol}$ retinol/1 was reduced from $20 \%$ to $16 \%$. The median plasma retinol concentration of the healthy or reference group was $1.33 \mu \mathrm{mol} / \mathrm{l}$, so the meta-analysis correction factors did not completely raise the retinol concentrations in the incubation and convalescent groups to that of the reference group. However, by calculating specific correction factors from the data for the HIVpositive subjects as shown in Table 3 , the median retinol concentration for the whole group is raised to that of the reference group and further reduces the number of low plasma retinol concentrations to $13 \%$. The prevalence of low plasma retinol concentrations is very close to the $15 \%$ prevalence that would be considered a public health problem (Sommer \& Davidson, 2002), but the carotenoid concentrations of the reference group (Table 4), which will be discussed later, do not suggest that vitamin A deficiency is a particular problem in this group.

\section{Acute-phase protein-corrected plasma ferritin concentrations as a measure of iron status}

Plasma ferritin concentrations for the HIV-1-positive adults are shown in Table 4 . They are grouped by gender and acute-phase status. The data illustrate a very large elevation of median ferritin concentrations in both the early (5-fold) and the late (3-fold) convalescence groups in

Table 2. Characterisation of subclinical inflammation and its effect on plasma retinol concentrations

\begin{tabular}{lllc}
\hline Group* & \multicolumn{1}{c}{$\begin{array}{c}\text { Stage of subclinical } \\
\text { inflammation }\end{array}$} & Raised acute-phase proteins & $\begin{array}{c}\text { Depression in plasma retinol } \\
\text { concentrations }(\%)\end{array}$ \\
\hline I & Healthy & None & None \\
II & Incubating or preclinical & C-reactive protein only & 13 \\
III & Early convalescence & C-reactive protein and $\alpha 1$-acid & 24 \\
IV & Late convalescence & $\alpha 1$-acid glycoprotein only & 11
\end{tabular}

*Group numbers define the stages of subclinical inflammation shown in Fig. 2. 
Table 3. Use of correction factors to remove influence of inflammation from plasma retinol concentrations from apparently-healthy HIV-1-positive adults

\begin{tabular}{|c|c|c|c|c|}
\hline & \multicolumn{4}{|c|}{ Groups separated by acute-phase proteins ${ }^{*}$} \\
\hline & $\begin{array}{l}\text { Reference or } \\
\text { healthy } n 66\end{array}$ & $\begin{array}{l}\text { Incubation* } \\
\quad n 18\end{array}$ & $\begin{array}{l}\text { Early convalescence } \\
\qquad n 65\end{array}$ & $\begin{array}{l}\text { Late convalescence* } \\
\qquad n 14\end{array}$ \\
\hline Median retinol $(\mu \mathrm{mol} / \mathrm{l})$ & $1 \cdot 33$ & $1 \cdot 25$ & $1 \cdot 01$ & $1 \cdot 10$ \\
\hline Meta-analysis correction factors $†$ & & $1 \cdot 13 \ddagger$ & $1 \cdot 24 \ddagger$ & $1 \cdot 11 \ddagger$ \\
\hline $\begin{array}{l}\text { Corrected median retinol concentration } \\
\text { for whole group using these correction factors } \neq\end{array}$ & & & $31 \mu \mathrm{mol} / \mathrm{l}$ & \\
\hline $\begin{array}{l}\text { Abnormal results }(<0.7 \mu \mathrm{mol} /) \text { following } \\
\text { correction: }\end{array}$ & & & $163(16 \%)$ & \\
\hline Present study correction factors§ & & $(1 \cdot 33 / 1 \cdot 25) 1.06$ & $(1.33 / 1 \cdot 01) 1.32$ & $(1 \cdot 33 / 1 \cdot 10) 1 \cdot 21$ \\
\hline $\begin{array}{l}\text { Corrected median retinol concentration for } \\
\text { whole group§ }\end{array}$ & & & $1 \cdot 33$ & \\
\hline Abnormal results following correction & & & $163(13 \%)$ & \\
\hline
\end{tabular}

*Subjects were allocated to the reference group unless plasma C-reactive protein concentration was $>5 \mathrm{mg} / \mathrm{l}$ and/or plasma $\alpha 1$-acid glycoprotein was $>1 \cdot 0 \mathrm{~g} / \mathrm{l}$ when subjects were allocated to the incubation (only C-reactive protein elevated), early convalescence (both C-reactive protein and $\alpha 1$-acid glycoprotein elevated) or late convalescence ( $\alpha 1$-acid glycoprotein only) groups.

†Refers to data from Thurnham et al. (2003).

†Retinol data in each group multiplied by respective correction factors, data were combined and corrected median value was calculated.

$\S$ Correction factors were calculated as shown, multiplied by plasma retinol concentrations in respective groups and the data were combined to calculate the corrected median retinol.

both genders. Concentrations of plasma ferritin differ markedly between the genders and therefore separate correction factors need to be calculated, producing corrected median ferritin concentrations of $166 \mu \mathrm{g} / \mathrm{l}$ and $41 \mu \mathrm{g} / \mathrm{l}$ for the whole groups of men and women respectively. Both values are still higher than the corresponding mean plasma ferritin concentrations of $84 \mu \mathrm{g} / \mathrm{l}$ and $31 \mu \mathrm{g} / \mathrm{l}$ reported for non-HIV-positive adults living in the same area of Kenya (Mwaniki et al. 2001), although the corrected result in the case of the women seems quite comparable. Furthermore, the number of cases of $\mathrm{Fe}$ deficiency in the women was found to be increased from eleven to twenty, which is an increase of $83 \%$ as a result of correcting for inflammation.
It is interesting to compare the Kenyan adult ferritin concentrations (Table 4) with those for Indonesian infants for whom Fe-deficiency anaemia is a well-recognised problem (Wieringa et al. 2002). Ferritin concentrations are found to be much lower in the infants than in the adults. In the Indonesian infants the plasma ferritin concentrations were also grouped using CRP and AGP, but using lesssensitive cut-offs of $10 \mathrm{mg} / \mathrm{l}$ and $1.2 \mathrm{~g} / \mathrm{l}$ respectively (Table 5). Even though the technique used was slightly less sensitive than that reported in the present paper, the elevations in ferritin associated with inflammation during convalescence are also very high. In the reference group $26 \%$ (eighty of 308) of infants were found to have $\mathrm{Fe}$ deficiency (ferritin $<12 \mu \mathrm{g} / \mathrm{l}$ ), whereas in the 184 infants

Table 4. Median concentrations for plasma ferritin, zinc, $\beta$-carotene and lutein and correction factors in apparently-healthy HIV-1-positive adults grouped by acute-phase status

\begin{tabular}{|c|c|c|c|c|c|c|}
\hline \multirow[b]{2}{*}{ Analyte } & \multicolumn{2}{|c|}{ Whole group } & \multicolumn{4}{|c|}{ Groups separated by acute-phase status* } \\
\hline & $\begin{array}{l}\text { Before } \\
\text { correction }\end{array}$ & $\begin{array}{c}\text { After } \\
\text { correction }\end{array}$ & $\begin{array}{l}\text { Reference } \\
\text { or healthy }\end{array}$ & Incubation* $^{*}$ & $\begin{array}{c}\text { Early } \\
\text { convalescence }^{*}\end{array}$ & $\begin{array}{c}\text { Late } \\
\text { convalescence* }\end{array}$ \\
\hline \multirow[t]{2}{*}{ Median ferritin $(\mu \mathrm{g} / \mathrm{l})$ for men $n \dagger$} & 488 & 166 & 166 & 262 & 1004 & 540 \\
\hline & 56 & 56 & 19 & 4 & 28 & 5 \\
\hline Correction factor & & & & $0.63 \ddagger$ & $0 \cdot 165$ & 0.307 \\
\hline \multirow{2}{*}{ Median ferritin $(\mu \mathrm{g} / \mathrm{l})$ for women $n \dagger$} & 90 & 41 & 41 & 50 & 213 & 107 \\
\hline & 107 & 107 & 47 & 14 & 37 & 9 \\
\hline Correction factor & & & & $0 \cdot 82$ & $0 \cdot 19$ & 0.38 \\
\hline Median Zn $(\mu \mathrm{mol} / \mathrm{l}) \S$ & $8 \cdot 8$ & $9 \cdot 4$ & $9 \cdot 3$ & $8 \cdot 6$ & $7 \cdot 9$ & $8 \cdot 4$ \\
\hline Correction factor & & & & 1.08 & $1 \cdot 17$ & 1.06 \\
\hline Median $\beta$-carotene $(\mu \mathrm{mol} / \mathrm{l}) \S$ & $0 \cdot 218$ & 0.319 & 0.320 & 0.323 & $0 \cdot 141$ & $0 \cdot 161$ \\
\hline Correction factor & & & & 0.99 & $2 \cdot 270$ & 1.988 \\
\hline Median lutein $(\mu \mathrm{mol} / \mathrm{l}) \S$ & 0.296 & 0.386 & 0.385 & 0.344 & 0.220 & 0.278 \\
\hline Correction factor & & & & $1 \cdot 119$ & $1 \cdot 750$ & $1 \cdot 385$ \\
\hline
\end{tabular}

*Subjects were allocated to the reference group unless plasma C-reactive protein concentration was $>5 \mathrm{mg} / \mathrm{l}$ and/or plasma $\alpha 1$-acid glycoprotein was $>1 \cdot 0 \mathrm{~g} / \mathrm{l}$ when subjects were allocated to the incubation (only C-reactive protein elevated), early convalescence (both C-reactive protein and $\alpha 1$-acid glycoprotein elevated) or late convalescence ( $\alpha 1$-acid glycoprotein only) groups.

†Nos. for groups in which genders are combined are shown in Table 3.

$\ddagger$ Specific correction factors are calculated as shown in Table 3.

$\S$ Values shown for combined gender groups, with $n 66$ (healthy), 18 (incubation), 65 (early convalescence), 14 (late convalescence). 
Table 5. Influence of inflammation on iron deficiency and low plasma zinc concentrations in Indonesian infants (modified from Wieringa et al. 2002)

\begin{tabular}{|c|c|c|c|c|}
\hline \multirow[b]{2}{*}{ Variable } & \multicolumn{4}{|c|}{ Groups separated by acute-phase status } \\
\hline & $\begin{array}{l}\text { Reference } \\
\text { or healthy }\end{array}$ & Incubation* & $\begin{array}{c}\text { Early } \\
\text { convalescence* }\end{array}$ & $\begin{array}{c}\text { Late } \\
\text { convalescence* }\end{array}$ \\
\hline Mean plasma ferritin $(\mu \mathrm{g} / \mathrm{l})$ & $14 \cdot 7$ & $32 \cdot 1$ & $34 \cdot 3$ & $34 \cdot 2$ \\
\hline \multicolumn{5}{|l|}{ Fe deficient $(>12 \mu \mathrm{g} \mathrm{Fe/l)}$} \\
\hline No. relative to total & $80 / 308$ & $2 / 61$ & $1 / 37$ & $9 / 86$ \\
\hline Percentage & 26 & $3 \cdot 3$ & $2 \cdot 7$ & $10 \cdot 5$ \\
\hline Mean plasma $\mathrm{Zn}(\mu \mathrm{mol} / \mathrm{l})$ & $15 \cdot 5$ & $13 \cdot 8$ & $13 \cdot 7$ & $14 \cdot 2$ \\
\hline $\begin{array}{l}\text { Plasma } \mathrm{Zn}<10.7 \mathrm{mmol} / \mathrm{l} \\
\text { No. relative to total }\end{array}$ & $34 / 308$ & $20 / 61$ & $10 / 37$ & $12 / 86$ \\
\hline Percentage & 11 & $33 \cdot 3$ & 27 & $15 \cdot 1$ \\
\hline
\end{tabular}

* Subjects were allocated to the reference group unless plasma C-reactive protein concentration was $>10 \mathrm{mg} / \mathrm{l}$ and/or plasma $\alpha 1$-acid glycoprotein was $>1 \cdot 2 \mathrm{~g} / \mathrm{l}$ when subjects were allocated to the incubation (only C-reactive protein elevated), early convalescence (both C-reactive protein and $\alpha 1$-acid glycoprotein elevated) or late convalescence ( $\alpha 1$-acid glycoprotein only) groups.

in whom there was inflammation only twelve cases $(7 \%)$ were detected. On the basis of the proportion in the reference group $(26 \%)$ the corresponding number should have been forty-eight cases in the group with inflammation, i.e. approximately thirty-six cases of $\mathrm{Fe}$ deficiency were missed. Thus, in both the adults and the infants with very different absolute concentrations of ferritin, Fe deficiency is obscured by the presence of inflammation.

\section{Influence of inflammation on plasma zinc concentrations}

Table 4 shows the median plasma $\mathrm{Zn}$ concentrations for the Kenyan HIV-1-positive adults grouped according to inflammatory status. In contrast to the large change in ferritin, inflammation is only associated with approximately a $12 \%$ reduction in plasma $\mathrm{Zn}$ concentrations (Table 4). However, plasma Zn concentrations are low in all groups, even in the group with no inflammation, and the correction factors only reduce the prevalence of low $\mathrm{Zn}$ concentrations $(<10 \mu \mathrm{mol} / \mathrm{l})$ from $75 \%$ to $59 \%$. However, the corrected prevalence values are still higher than those reported in the Nutrition Survey (Mwaniki et al. 2001), in which the prevalence of low $\mathrm{Zn}$ concentrations for the country as a whole was found to be $46 \%$ and $52 \%$ in men and women respectively.

In the Indonesian data (Wieringa et al. 2002) plasma $\mathrm{Zn}$ concentrations in all groups are higher than those of the HIV-1-positive Kenyan adults. However, depression in plasma $\mathrm{Zn}$ concentrations associated with current inflammation in the Indonesian infants is also approximately $12 \%$ by comparison with the reference group (Table 5). Wieringa et al. (2002) used a slightly higher cut-off of $10 \cdot 7 \mu \mathrm{mol} / \mathrm{l}$, so the results are not directly comparable, but in both these studies the effects of current inflammation on plasma $\mathrm{Zn}$ concentrations are relatively small and other factors such as the high cereal intake and the HIV infection must be considered to explain the low $\mathrm{Zn}$ concentrations in the Kenyan adults.

\section{Influence of inflammation on plasma carotenoid concentrations}

Table 4 shows the plasma concentrations of $\beta$-carotene and lutein in the Kenyan adults. Concentrations of both carotenoids in the healthy group are comparable with those found in Western populations, suggesting that vitamin A deficiency is not a problem in this group (International Agency for Research on Cancer Working Group, 1998). However, there is a large depression in both median plasma $\beta$-carotene $(>50 \%)$ and lutein (approximately $40 \%$ ) concentrations associated with early and late convalescence but $<10 \%$ during the incubation period. Plasma carotenoid concentrations are strongly linked to dietary intake, hence the relatively small effect of the incubation period on carotenoid concentrations is not surprising. Appetite is frequently depressed by disease and the low concentrations during convalescence will be at least partly a result of reduced dietary intakes during illness.

There have been a number of studies (Kritchevsky et al. 2000; Erlinger et al. 2001; Cser et al. 2004) that report associations between low concentrations of $\beta$-carotene and infection or stress of one form or another. In all cases inverse correlations between plasma CRP and $\beta$-carotene concentrations have been found. Low plasma $\beta$-carotene concentrations have also been shown to increase the risk for heterosexual HIV acquisition in patients with sexuallytransmitted diseases in India (Mehendale et al. 2001) and to be associated with an increased risk of death during HIV infection in Ugandan infants (Melikian et al. 2001). However, the findings of Kritchevsky et al. (2000) and Erlinger et al. (2001) suggest that the association between $\beta$-carotene and disease risk is probably confounded by inflammation.

Cser et al. (2004), on the other hand, report the concentrations of several plasma carotenoids in children with clinical infections. They make the interesting observation that the mean provitamin A carotenoid concentration for children with infection is only $20 \%$ of that for a group of healthy controls of similar ages. In contrast, the mean concentration of non-provitamin A carotenoids for the children with infection is only half that for the healthy children. While some of this difference may be related to the different half-lives of the carotenoids ( $\beta$-carotene $<12 \mathrm{~d}$ and zeaxanthin and lutein 33-61d; Rock et al. 1992), the authors report that an altered dietary intake as a result of the disease would only have been effective 24-72 $\mathrm{h}$ before the blood was taken. The concentration 
of plasma $\beta$-carotene in the sick children is strongly associated with the severity of infection and no plasma $\beta$-carotene could be detected in those children with severe and very severe infections (twenty-eight of fifty-five, $62 \%$ ). These data suggest that turnover of carotenoids during inflammatory disease is accelerated. However, lutein was detected in all samples, therefore it seems unlikely that the elevated turnover rates were only a result of non-specific oxidative damage, and the possibility that the metabolism of plasma $\beta$-carotene to retinol or other retinoids during inflammation is increased cannot be excluded.

\section{Discussion and implications}

High micronutrient requirements and frequent sickness increase the risk of deficiency among infants and children in many developing countries. However, while micronutrient deficiencies may gradually deplete the body's reserves and eventually lower biomarkers of micronutrient status, the inflammatory response can very rapidly alter the same biomarkers. Even the apparently-healthy child can show evidence of inflammation, thus the net concentration of biomarkers in the blood of such children is a result of a combination of the dietary status and any lingering effects of inflammation. In the present paper data have been taken from apparently-healthy HIV-1-positive adults and using methods developed to examine the influence of inflammation on plasma retinol concentrations (Thurnham et al. 2003) it has been confirmed that these methods can be adapted to examine vitamin A status in the HIV-1-positive adults and that the same technique can be used to examine plasma ferritin, $\mathrm{Zn}, \beta$-carotene and lutein concentrations. In the case of ferritin and $\mathrm{Zn}$ the corrected data have become much more similar to expected concentrations for those biomarkers obtained in comparable HIV-negative subjects in Kenya (Mwaniki et al. 2001) and the relative changes in these biomarkers in response to inflammation show similarities with a comparable analysis of data from apparently-healthy Indonesian infants (Wieringa et al. 2002). In the case of the carotenoids the concentrations are surprisingly low during the convalescent phase. However, it has been suggested that a reduction in plasma carotenoid concentrations is rapid in disease and much greater than would be expected from altered food intake (Cser et al. 2004) and/or natural turnover (Rock et al. 1992) alone. These results provide even stronger evidence for the questionability of studies in which infection rates or biological stresses are high and in which plasma $\beta$-carotene concentrations are used as a marker of absorption.

In conclusion, the potentially large influence of subclinical inflammation on plasma retinol, $\mathrm{Zn}$, ferritin and the carotenoid concentrations emphasises the urgent need to monitor inflammation where these biomarkers are used to assess nutritional status. Furthermore, the association between inflammatory markers and changes in nutritional biomarkers indicates that caution should be exercised before conclusions are drawn about poor nutrition and increased disease risks. Finally, the different response to supplements by individuals with elevated as compared with normal inflammatory markers (Baeten et al. 2002) needs better understanding, as it may help to improve our interpretation of or prevent future trials with adverse effects on health such as the trials with vitamin A palmitate and $\beta$-carotene (Villamor et al. 2005), $\mathrm{Fe}$ (Oppenheimer et al. 1986) and $\beta$-carotene (Heinonen et al. 1994).

\section{Acknowledgements}

We thank UNICEF and the Dutch Government for providing funds to do the work in Kenya under project number SSA/KENB/2002/00002302-03 and Mrs Lilian Selenje, Programme Officer (Micronutrients) for UNICEFESARO for help with administration. The authors also thank Mr Fred Alumasa and Miss Faith Mugai for their work in the field. Our thanks also go to Mr Joseph Njoroge and Mr James Muthotho (Nakuru) and Dr Macharia Githigia (Nanyuki ) for their support at the field sites, $\mathrm{Mr}$ Peter Waithaka and Mr Ronald Njagi for ferritin analyses, Mr Munyoki for $\mathrm{Zn}$ measurements and Mr Erastus Muniu for data analysis.

\section{References}

Baeten JM, McClelland RS, Richardson BA, Bankson DD, Lavreys L, Wener MH, Overbaugh J, Mandaliya K, NdinyaAchola JO, Bwayo JJ \& Kreiss JK (2002) Vitamin A deficiency and the acute phase response among HIV-1-infected and -uninfected women in Kenya. Journal of Acquired Immune Deficiency Syndromes 31, 243-249.

Ballew C, Bowman BA, Sowell AL \& Gillespie C (2001) Serum retinol distribution in residents of the United States: third National Health and Nutrition Examination Survey, 19881994. American Journal of Clinical Nutrition 73, 586-593.

Beisel WR (1976) Trace elements in infectious processes. Medical Clinics of North America 60, 831-849.

Brown KH, Lanata CF, Yuen ML, Peerson JM, Butron B \& Lonnerdal B (1993) Potential magnitude of misclassification of a population's trace element status due to infection: example from a survey of young Peruvian children. American Journal of Clinical Nutrition 58, 549-554.

Cser MA, Majchrzak D, Rust P, Sziklai-Laszlo I, Kovacs I, Bocskai E \& Elmadfa I (2004) Serum carotenoid and retinol levels during childhood infections. Annals of Nutrition and Metabolism 48, 156-162.

De Luca LM, Glover J, Heller J, Olson JA \& Underwood BA (1997) Guidelines for the Eradication of Vitamin A Deficiency and Xerophthalmia. vol. VI, Recent Advances in the Metabolism and Function of Vitamin A and their Relationship to Applied Nutrition, pp. 1-44. New York: The Nutrition Foundation.

Department of Health (1991) Dietary Reference Values for Food Energy and Nutrients for the United Kingdom. Report on Health and Social Subjects no. 41. London: H. M. Stationery Office.

Dobosz S \& Marczynska M (2004) The most common pathologic syndromes in HIV-infected children. HIV AIDS Reviews 3, 51-53.

Erlinger TP, Guallar E, Miller ER, Stolzenberg-Solomon R \& Appel LJ (2001) Relationship between systemic markers of inflammation and serum $\beta$-carotene levels. Archives of Internal Medicine 161, 1903-1908. 
Filteau SM, Morris SS, Raynes JG, Arthur P, Ross DA, Kirkwood B, Tomkins AM \& Gyapong JO (1995) Vitamin A supplementation, morbidity, and serum acute-phase proteins in young Ghanaian children. American Journal of Clinical Nutrition 62, 434-438.

Golden MHN (1991) The nature of nutritional deficiency in relation to growth failure and poverty. Acta Paediatrica Scandinavica 374, 95S-110S

Gregory JR, Collins DL, Davies PSW, Hughes JM \& Clarke PC (1995) National Diet and Nutrition Survey: Children Aged 1 1/2 to 4 1/2 Years. London: H. M. Stationery Office.

Gregory JR, Foster K, Tyler H \& Wiseman M (1990) The Dietary and Nutritional Survey of British Adults. London: H. M. Stationery Office.

Gregory JR, Lowe S, Bates CJ, Prentice A, Jackson LV, Smithers G, Wenlock R \& Farron M (2000) National Diet and Nutrition Survey of Children 4 to 18 Years. Vol. 1: Report of the Diet and Nutrition Survey. London: The Stationery Office.

Heinonen OP, Huttunen JK, Albanes D \& ATBC Cancer Prevention Study Group (1994) The effect of vitamin E and beta carotene on the incidence of lung cancer and other cancers in male smokers. New England Journal of Medicine 330, $1029-1035$.

International Agency for Research on Cancer Working Group (1998) Carotenoids, 1st ed. Lyon, France: WHO International Agency for Research on Cancer.

Kritchevsky SB, Bush AJ, Pahor M \& Gross MD (2000) Serum carotenoids and markers of inflammation in non-smokers. American Journal of Epidemiology 152, 1065-1071.

Louw JA, Werbeck A, Louw MEJ, Kotze TJvW, Cooper R \& Labadarios D (1992) Blood vitamin concentrations during the acute-phase response. Critical Care Medicine 20, 934-941.

Mburu ASW, Mwaniki DL, Thurnham DI, Selenje L, de Wagt A, Muniu EM, Friis H. \& Krarup H (2004) Effects of Multimicronutrient Supplements and Food Aid Rations on the Nutritional Status and Health of HIV + Adults (MINIFAR). Nairobi, Kenya: CPHR-KEMRI.

Mehendale SM, Shepherd ME, Brookmeyer RS, Semba RD, Divekar AD, Ganakhedar RR, Joshi S, Risbud AR, Paranjape RS, Gadkari DA \& Bollinger RC (2001) Low carotenoid concentrations and the risk of HIV seroconversion in Pune, India. Journal of Acquired Immune Deficiency Syndromes 26, 352-359.

Melikian G, Mmiro F, Ndugwa C, Perry G, Jackson JB, Garrett E, Tielsch JM \& Semba RA (2001) Relation of vitamin A and carotenoid status to growth failure and mortality among Ugandan infants with human immunodeficiency virus. Nutrition 17, 567-572.

Mitra AK, Alvarez JO, Wahed MA, Fuchs GJ \& Stephensen CB (1998) Predictors of serum retinol in children with shigellosis. American Journal of Clinical Nutrition 68, 1088-1094.

Mwaniki DL, Omwega AM, Miniu EM, Mutunga JN, Akelola R, Shako BR, Gotink MH \& Pertet AM (2001) Anaemia and Status of Iron, Vitamin A and Zinc in Kenya. The 1999 National Survey Report. Nairobi, Kenya: Ministry of Health.

Northrop-Clewes CA, Lunn PG \& Downes RM (1994) Seasonal fluctuations in vitamin A status and health indicators in Gambian infants. Proceedings of the Nutrition Society 53, 144A.

Oppenheimer SJ, Gibson FD, MacFarlane SBJ, Moody JB, Harrison C, Spencer A \& Bunari O (1986) Iron supplementation increases prevalence and effects of malaria: report on clinical studies in Papua New Guinea. Transactions of the Royal Society of Tropical Medicine and Hygiene $\mathbf{8 0}$, 603-612.

Panter-Brick C, Lunn PG, Baker R \& Todd A (2001) Elevated acute-phase protein in stunted Nepali children reporting low morbidity: different rural and urban profiles. British Journal of Nutrition 85, 125-131.

Paracha PI, Jamil A, Northrop-Clewes CA \& Thurnham DI (2000) Interpretation of vitamin A status in apparently-healthy Pakistani children using markers of sub-clinical infection. American Journal of Clinical Nutrition 72, 1164-1169.

Pilch SM (editor) (1985) Guidelines for interpretative criteria In Assessment of the Vitamin A Nutritional Status of the U.S. Population Based on Data Collected in the Health and Nutrition Examination Surveys, pp. 17-23. Bethesda. MA: FASEB

Reddy V, Bhaskaram P, Raghuramulu N, Milton RC, Rao V, Madhusudan J \& Radha Krishna KV (1986) Relationship between measles, malnutrition, and blindness: a prospective study in Indian children. American Journal of Clinical Nutrition 44, 924-930.

Rock CL, Swenseid ME, Jacob RA \& McKee RW (1992) Plasma carotenoid levels in human subjects fed a low carotenoid diet. Journal of Nutrition 122, 96-100.

Rosales FJ, Ritter SJ, Zolfaghari R, Smith JE \& Ross AC (1996) Effects of acute inflammation on plasma retinol, retinolbinding protein, and its messenger RNA in the liver and kidneys of vitamin A sufficient rats. Journal of Lipid Research 37, 962-971.

Rousham EK, Northrop-Clewes CA \& Lunn PG (1998) Maternal reports of child illness and the biochemical status of the child: the use of morbidity interview in rural Bangladesh. British Journal of Nutrition 80, 451-456.

Rowland MG, Cole TJ \& Whitehead RG (1977) A quantitative study into the role of infection in determining nutritional status in Gambian village children. British Journal of Nutrition 37, 441-450.

Sepulveda J, Willett W \& Munoz A (1988) Malnutrition and diarrhea. A longitudinal study among urban Mexican children. American Journal of Epidemiology 127, 365-376.

Shankar AH, Genton B, Semba RA, Baisor M, Paino J, Tamja S et al. (1999) Effect of vitamin A supplementation on morbidity due to Plasmodium falciparum in young children in Papua New Guinea: a randomised trial. Lancet 354, 203-209.

Sommer A \& Davidson FR (2002) Assessment of control and vitamin A deficiency: the Annecy accords. Journal of Nutrition 132, 2845S-2851S.

Thurnham DI (1997) Impact of disease on markers of micronutrient status. Proceedings of the Nutrition Society 56, 421-431.

Thurnham DI, McCabe GP, Northrop-Clewes CA \& Nestel P (2003) Effect of subclinical infection on plasma retinol concentrations and assessment of prevalence of vitamin A deficiency: meta-analysis. Lancet 362, 2052-2058.

Thurnham DI \& Northrop-Clewes CA (2004) Effects of infection on nutritional and immune status, In Diet and Human Immune Function, pp. 35-64 [DA Hughes, LG Darlington and A Bendich, editors]. Totowa, NJ: Humana Press.

Thurnham DI, Northrop-Clewes CA, McCullough FSW, Das BS \& Lunn PG (2000) Innate immunity, gut integrity and vitamin A in Gambian and Indian infants. Journal of Infectious Diseases 182, S23-S28.

Thurnham DI \& Singkamani R (1991) The acute phase response and vitamin A status in malaria. Transactions of the Royal Society of Tropical Medicine and Hygiene 85, 194-199.

Villamor E, Saathoff E, Bosch RJ, Hertzmark E, Baylin A, Manji K, Msamanga G, Hunter DJ \& Fawzi WW (2005) Vitamin supplementation of HIV-infected women improves postnatal child growth. American Journal of Clinical Nutrition 81, 880-888.

Wieringa FT, Dijkhuizen MA, West CE, Northrop-Clewes CA \& Muhilal (2002) Estimation of the effect of the acute phase response on indicators of micronutrient status in Indonesian infants. Journal of Nutrition 132, 3061-3066. 